\title{
O ensino do turismo através do cinema
}

\section{Tourism teaching through cinema}

\author{
Lorena Angélica Mancini (MANCINI, L. A.) ${ }^{*}$ \\ Michele Leandro da Costa (COSTA, M. L. da) ${ }^{*}$, \\ Sonia Maria Carrasco Guilen (GUILEN, S. M. C.) ${ }^{* * *}$
}

RESUMO - O presente artigo é resultado do Projeto de Extensão Cinema e Educação, desenvolvido na Universidade Estadual do Paraná - UNESPAR - Campus Apucarana (FECEA), com parceria do Centro de Estudos Aplicados ao Turismo da UNESPAR campus Apucarana (CEETUR). Na região atendida pelo projeto em específico não se teve conhecimento de atividades semelhantes, fato este que fez com que houvesse muitos interessados em participar. No projeto se buscou atuar na prática analisando os benefícios do uso do cinema para a prática educativa. O presente artigo objetivou analisar esta relação especificamente para o curso de Turismo, verificando como esta ferramenta estava sendo utilizada pelos professores, visando assim melhor aproveitamento desta arte na área. Quanto a metodologia do estudo em questão trabalhou-se com encontros quinzenais durante os meses de maio e junho do ano de 2016. Os filmes foram selecionados considerando suas temáticas unindo conteúdos a serem trabalhados e discutidos, relacionando-os com as áreas envolvidas no curso. Os filmes apresentados foram: Diários de Motocicleta (2004); Falando Grego (2009); Iracema - uma transa Amazônica (1975) e Comer, Rezar e Amar (2010). Após cada exibição foram feitas discussões com um mediador e os participantes e aplicado um questionário avaliativo. Concluiu-se que muitas vezes o filme ainda estava sendo usado como motivação para introduzir determinados conteúdos, porém constatando-se haver alguns professores que relataram as experiências associando educação e cinema argumentando ser um instrumento interessante tornando as aulas muito mais produtivas e dinâmicas, ampliando a capacidade de reflexão dos alunos, despertando o senso crítico da realidade.

Palavras-chave: Turismo; Cinema; Educação.

\footnotetext{
*Formação: Graduada em Turismo e Hotelaria pela UNOPAR, Especialização em Turismo, Políticas Públicas e Desenvolvimento Local pela PUC- Minas e em Metodologia da Ação Docente com ênfase no Ensino Superior pela Faccar, Mestrado em Turismo e Hotelaria pela Univali. Atividade profissional: Professora do Curso de Turismo da UNESPAR - campus de Apucarana. Endereço físico para correspondência: Rua Monteiro Lobato 895. CEP: 86600-125 - Rolândia - Paraná - Brasil. Email: lo_mancini@hotmail.com

** Formação: Graduada em Turismo e Hotelaria pela Univali, Especialização em Gestão de Cerimonial, Protocolo e Eventos (CESUMAR). Atividade profissional: Professora do Curso de Turismo da UNESPAR - campus de Apucarana. Endereço físico para correspondência: Rua José Maria de Paula, 1650/ap.101-A, Centro. CEP: 86900-000 - Jandaia do Sul - Paraná - Brasil. E-mail: m_leandro_costa@hotmail.com

*** Formação: Graduada em História pela Fafiman, Especialização em Deficiência Mental pela Fafijan, Mestrado em Concentração Formação do Professor (FAFIJAN). Atividade profissional: professora do Curso de Turismo da UNESPAR - campus de Apucarana. Endereço físico para correspondência: Praça Interventor Manoel Ribas, 125, ap. 1101, Centro. CEP: 86800-680 - Apucarana - Paraná - Brasil. E-mail: smcguilen@yahoo.com.br
} 
ABSTRACT - The present paper is a result of an Education and Cinema Extension Project, developed at UNESPAR (Paraná State University) - Apucarana Campus (FECEA), in partnership with Tourism Applied Studies Center (CEETUR) of the same university. In the attended region there aren't any records of similar activities, and because of that the project had plenty of enrolled interested people. In this project it has been aimed to analyze the benefits of cinema to the educative practice. Then this paper goal was to analyze this relation specifically for Tourism Course purposes and verify how this tool was being used by professors, in order to have a better exploitation of such art in this area. The methodology used was biweekly meetings during May and June of 2016. The movies were organized by theme and subjects to be discussed, relating them to topics and areas relevant to the course. The exhibited movies were: Diários de Che Guevara (2004), My Life in Ruins (2009), Iracema (1975) and Eat Pray Love (2010). After each exhibition a mediator proposed some discussions about the movie and it was applied an assessment form to each participant. It could be concluded that many times a movie was still being used as a motivation to introduce certain topics, but it was verified that some professors reported experiences connecting education and cinema, by claiming it is an interesting tool that makes the classes more productive and dynamic, expanding students' reflection capacity and increasing their argumentative sense on reality.

Key words: Tourism; Cinema; Education. 


\section{INTRODUÇÃO}

A velocidade das transformações sociais ocorridas nas últimas décadas tem influenciado a vida das pessoas principalmente no tocante à educação, modificando o modo de agir e pensar das pessoas. É inegável a facilidade com que crianças, jovens e adultos, têm acesso às informações que se espalham de forma quase simultânea por todo o mundo através de diversos mecanismos tecnológicos e midiáticos criando novos ambientes educacionais que não necessariamente o ambiente escolar.

A abordagem do tema Cinema e Educação voltada para o curso de Turismo justifica-se pela importância detectada de se pesquisar sobre o tema e de alguma forma contribuir para o conhecimento do processo, pelo fato de a imagem ser um mecanismo de suma importância para a atividade turística, principalmente por esta ser uma área em que a criatividade audiovisual é um fator predominantemente evidente, que mexe com o inconsciente e o imaginário do indivíduo influenciando-o nas tomadas de decisões.

A intangibilidade do produto turístico causa em alguns consumidores uma espécie de insegurança, pois o produto ou serviço turístico só podem ser experimentados após sua compra, assim as imagens seriam uma forma de acalentar e de sensibilizar a percepção humana, tentando diminuir o aspecto de intangível que o produto turístico possui.

Tendo como objetivo geral "Inserir a arte do Cinema no processo de ensinoaprendizagem por meio de uma visão multidisciplinar como um meio de aproximar o público Acadêmico/Professores/Comunidade da narrativa audiovisual, fazendo a ligação entre a educação, cultura, arte, história e música"; no Projeto de Extensão Cinema e Educação se buscou estudar e analisar os benefícios do uso de filmes para a prática educativa, assim como orientar outros profissionais interessados, especialmente educadores, para o melhor aproveitamento da arte cinematográfica. Como menciona Napolitano (2003, p. 11-12), é uma forma de "Ajudar a escola a reencontrar a cultura ao mesmo tempo cotidiana e elevada, pois o cinema é o campo no qual a estética, o lazer, a ideologia e os valores sociais mais amplos são sintetizados numa mesma obra de arte".

Com relação ao curso de Turismo, foco deste recorte do projeto - observou-se que cada vez mais o cinema estava se tornando uma ferramenta de uso no marketing de empresas ligadas à área, como forma de promover seus pacotes de viagens. Porém, a 
apresentação de produções cinematográficas de diferentes épocas, gêneros e países, possibilitam não só explorar o merchandising, como também a realização de atividades de forma interdisciplinar, com a mediação dos professores objetivando o aprimoramento do senso crítico e atitude crítica-reflexiva dos alunos.

No que se refere ao cinema, percebeu-se que este estava sendo utilizado em alguns países europeus e norte-americanos, como mecanismo de divulgação e promoção dos destinos turísticos. A adoção de tal estratégia de divulgação tem aumentado o número de turistas nos países que as utilizam, seja pelos atrativos turísticos mostrados nos filmes, seja pelas personagens, pelas narrativas ou por outros motivos (BRASIL, 2007). O fato é que em muitos países se observou o aumento do número de turistas após sua exposição no cinema, haja vista que existem muitos filmes que têm feito um excelente trabalho em retratar locais turísticos que capturam os olhos dos telespectadores (BRASIL, 2010).

\section{CINEMA E EDUCAÇÃO}

Aprender com a estética na qual o cinema está incluído - estimula a reflexão do

aluno. À medida que as emoções desempenham papéis fundamentais na aprendizagem de atitudes e mudança de comportamento, os professores devem estimular o domínio afetivo dos alunos. Como os sentimentos existem antes dos conceitos, o caminho afetivo é um caminho crítico para o processo racional de aprendizado. O cinema é a versão audiovisual da narrativa. Ele melhora as emoções e, portanto, estabelece as bases para a transmissão de conceitos.

As experiências apresentadas em um filme agem como memórias emocionais para desenvolver atitudes e mantê-las como referência reflexiva nas atividades e eventos diários. Promover a reflexão é o principal objetivo deste conjunto de ensino cinematográfico.

Não se trata apenas de mostrar ao público como incorporar uma atitude particular, mas sim promover sua reflexão e fornecer um fórum de discussão. Esta atividade enquanto metodologia oferece um ambiente especial para promover discussões, ajuda os professores a melhorar seu autoconhecimento e desenvolver 
relações mais estreitas com colegas e alunos através do domínio afetivo (BLASCO et al., 2006).

\subsection{HISTÓRIA DO CINEMA}

Os filmes desenvolveram-se gradualmente de uma novidade efêmera para uma das ferramentas mais importantes de comunicação, entretenimento e mídia de massa no século XX e XXI (WEBCINE, 1998). Os filmes cinematográficos tiveram um impacto substancial nas artes, na tecnologia e na política (WEBCINE, 1998).

As pinturas rupestres encontradas nas cavernas já demonstravam uma tentativa do homem em registrar acontecimentos. Os primeiros registros de movimento que se têm notícia datam de 5000 a.C. na China, onde faziam o teatro de sombras que representavam cenas com figuras recortadas demonstrando histórias em movimento sobre príncipes, heróis e dragões. (COSTELA, 2002).

Com o avanço tecnológico, vários inventores tiveram a possibilidade de criar aparelhos capazes de captar e registrar o movimento, entre eles, a criação do princípio da câmara escura por Leonardo Da Vinci no século XVI e a criação da lanterna mágica, máquina criada por Athanasius Kirchner no século XVII que era capaz de projetar imagens desenhadas em lâminas de vidro (FURUNO, 2010). Mas foi creditado a William Kennedy Laurie Dickson, engenheiro-chefe dos laboratórios Edison, a invenção de uma espécie de tira de celuloide contendo uma sequência de imagens, a partir de um método de fotografar e projetar imagens em movimento. (FURUNO, 2010)

Em 1893, na Feira Mundial de Chicago, Thomas Edison apresentou ao público duas invenções pioneiras baseadas nesta inovação: o Kinetograph, a primeira câmera fotográfica prática e o Kinetoscope, este último era um armário no qual um loop contínuo da película de celuloide de Dickson (alimentado por um motor elétrico) foi iluminado por uma lâmpada incandescente e visto através de uma lente de aumento (WEBCINE, 1998).

Bernardet (2006), narra a história da sétima arte a partir da primeira exposição do cinema, realizada por meio do cinematógrafo, máquina inventada pelos irmãos Lumiére, para uso de pesquisas científicas a qual foi criada para reproduzir movimentos. Essa máquina proporcionou às pessoas a primeira exibição pública do cinema, 
exatamente no dia 28 de Dezembro de 1895, na cidade de Paris (FURUNO, 2010). Os primeiros filmes eram curtos e mudos, mas, nessa primeira exibição, o que mais impressionou o público foram as imagens de um trem que enchia a tela dando a impressão de que iria se projetar sobre a plateia, causando um enorme susto aos espectadores (BERNARDET, 2006). Portanto, neste momento, nascia na história da humanidade a grande arte do século XX, ou seja, o cinema.

\subsection{ENSINANDO ATRAVÉS DE FILMES}

A sociedade vem passando por diversas transformações que refletem diretamente na vida, hábitos e comportamentos dos cidadãos. Entre estas transformações o rápido e fácil acesso a uma vasta gama de informações que se espalham por todo o mundo através de diversos mecanismos tecnológicos tem reflexo direto na educação, criando novos ambientes e instrumentos educacionais.

Holleben (s./d., s./p.) explica que é inegável que a modernidade trouxe inúmeros avanços à humanidade, e que mesmo estes não estando disponíveis a todos igualmente, deve-se reconhecer que "as novas tecnologias revolucionam a comunicação, difundem a informação, modificam processos de trabalho, imprimem novas formas de pensar e fazer educação".

Nessa perspectiva Marcello e Fisher (2011, p. 506), colocam que, diante de tantas transformações sociais, sobretudo num mundo no qual "múltiplas e diferenciadas imagens atravessam nosso cotidiano de maneira sem igual", é prioridade ampliar e modificar os processos educacionais.

Complementando Klammer et al. (2006, p. 1) afirmam que:

[...] a escola não é mais o único local de aprendizagem e nem o professor o único detentor do conhecimento ou da informação, aspecto esse que revela a necessidade de uma ação pedagógica associada aos muitos canais de comunicação existentes no cotidiano dos alunos, dentre os quais se inclui o cinema.

O uso de filmes no ensino é uma maneira eficaz de alcançar o domínio afetivo das pessoas, promover atitudes reflexivas e ligar o aprendizado às experiências. Ensinar com filmes desencadeia emoções e permite que surjam perguntas, expectativas e dilemas tanto para alunos como para professores. Os filmes fornecem um modelo 
narrativo fundamentado no aprendizado, pois facilitam a integração das emoções na visualização da experiência e ajudam os alunos a entender e reconhecer a principal mensagem sobre as atitudes e valores demonstrados pelas personagens.

Segundo Vesce (2017, s./p.):

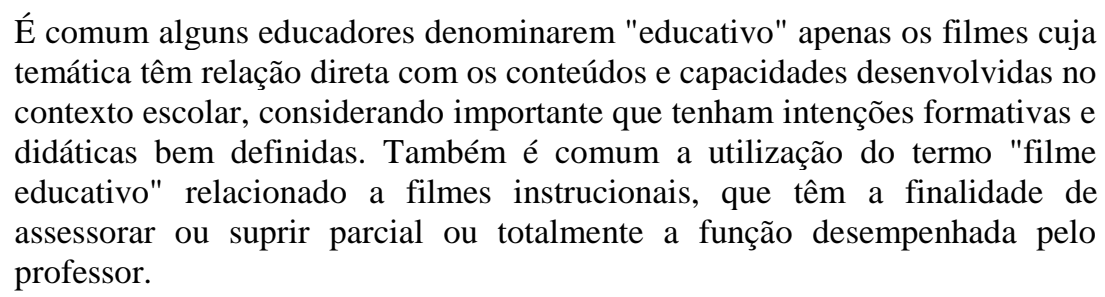

Essas duas situações, segundo Vesce (2017), constituem um reducionismo que limita a utilização do cinema como instrumento didático-pedagógico. "Qualquer filme retrata o pensamento e a criação humana em um determinado modelo social e momento histórico, e, portanto, educa a quem o assiste, gerando uma reflexão e uma impressão sobre o mundo" (VESCE, 2017, s./p.).

Desta forma, os filmes criam um novo processo de aprendizagem e a experiência atua como memória emocional para as atitudes em desenvolvimento dos alunos e permite-lhes prosseguir as atividades diárias. Promover a reflexão é o objetivo principal desse conjunto de ensino cinematográfico, porém o objetivo não é mostrar ao público como incorporar uma atitude particular, mas sim incentivar a reflexão e favorecer um fórum para discussão.

\subsection{PAPEL DO PROFESSOR NA UTILIZAÇÃO DE FILMES COMO PRÁTICA PEDAGÓGICA}

Os resultados educacionais não se materializam simplesmente por assistir filmes. Pessoas que frequentam o cinema o tempo todo e veem as mesmas cenas, embora possam ter emoções semelhantes, falta-lhes o processo reflexivo. É aqui que a competência e as habilidades de ensino do professor entram em jogo, isto é, juntando todas as cenas e promovendo a reflexão através de comentários e pensamentos pessoais, mesmo que as questões abertas não sejam respondidas. 
Nesse sentido, não cabe ao professor ignorar as informações trazidas de fora por intermédio dos meios de comunicação, mas sim usufruir de tais informações e incorporá-las de forma ativa e construtiva, no intuito de dinamizar o processo de ensino aprendizagem. (KLAMMER et al., 2006 s./p.)

Segundo Franco ${ }^{1}$ (apud PRETTO, 1996, p. 117), a escola "não deve competir com a mídia, mas travar com ela um jogo dialético". Entende-se aqui como jogo dialético com a mídia a importância de uma parceria do professor com as tecnologias, as mesmas que permeiam a vida de alunos e professores.

\begin{abstract}
Nesse contexto, o papel do professor é estabelecer com o aluno, relações indispensáveis entre os conteúdos adquiridos na escola e as "leituras" do cotidiano. Mas, se o cinema ou qualquer outro recurso multimídia for utilizado tão somente como um instrumento, este não passará de mais um recurso didático-pedagógico reduzindo, portanto, as múltiplas possibilidades de seu uso (KLAMMER et al., 2006 s./p.)
\end{abstract}

Napolitano (2003) ressalta que inserir o cinema como recurso didático pedagógico é oferecer à escola o reencontro com a cultura cotidiana e elevada ao mesmo tempo, ou seja, o cinema é a área na qual a estética, o lazer, a ideologia e os valores sociais mais abrangentes são compostos numa só obra de arte. Não basta apenas inserir projeções nas práticas escolares, é preciso compreendê-las, não como um novo recurso instrutivo, mas como um princípio, que pode colaborar para a construção do conhecimento de uma nova forma.

Ao relacionar o conteúdo exposto anteriormente para os cursos de turismo brasileiros, sejam esses técnicos ou de graduação, verifica-se a possibilidade em trabalhar com obras cinematográficas explorando várias disciplinas através da interdisciplinaridade. Atividades bem planejadas e organizadas por professores capacitados podem contribuir e muito para o enriquecimento cultural, crítico e reflexivo dos alunos como exposto nos itens subsequentes.

\title{
3 TURISMO
}

Observa-se que o turismo se consolida como uma das mais importantes atividades com as quais o homem está envolvido, seja de forma profissional, seja como

\footnotetext{
${ }^{1}$ FRANCO, M. Cinema e educação. Imagem, Tecnologia, Educação, Rio de Janeiro, n.p 1, ago./out. 1989.
} 
o próprio turista. Nakashima e Calvente (2016, p. 18) colocam que o turismo é visto como "um dos mais importantes setores na sociedade contemporânea e a principal atividade econômica de vários países".

Portanto mais do que negócio ou atividade de lazer, o turismo é uma profusão de elementos, fenômenos e relações que está relacionado ao consumo, à cultura, ao conhecimento, e a uma prática social da contemporaneidade (BARRETTO, 2003). A modernidade é dinâmica determinando padrões de comportamento complexos e a necessidade de viajar está implícita neles. Este elemento comportamental cria espaço para atividades econômicas que se dediquem à organização de produtos e serviços que proporcionem ao homem a oportunidade de atender esta sua necessidade de forma mais prazerosa.

Dessa forma, no entender de Mota (2001, p. 43):

Turismo é um fenômeno socioeconômico que consiste no deslocamento temporário e voluntário de uma ou mais pessoas que, por diversos fatores que envolvem a motivação humana, saem do seu local de residência habitual para outro, gerando múltiplas inter-relações de importância cultural, socioeconômica e ecológica entre os núcleos emissores e receptores.

Ao longo do tempo, diversas foram as tentativas para conceituar o Turismo de uma forma única. No entanto, por ser uma atividade multidisciplinar acaba sofrendo interferências conceituais das diferentes áreas que compõem o Turismo. Para Perlin (2010), o conceito de turismo continua evoluindo, agregando maior abrangência e criando um mercado cada vez mais amplo. Apesar de existirem inúmeros conceitos, todos possuem características semelhantes, como a necessidade de locomoção, o fato da estadia não ser permanente, a necessidade de um motivo para a viagem, a satisfação do visitante, entre outros.

Porém, o conceito mais aceito descreve o turismo com o sendo:

As atividades que as pessoas realizam durante suas viagens e estadias em lugares diferentes de sua moradia habitual, por um período de tempo contínuo inferior a um ano com fins de lazer, por negócios ou outros motivos, não relacionados com o exercício de uma atividade remunerada no lugar visitado (OMT² apud DIAS; AGUIAR, 2002, p. 24).

\footnotetext{
${ }^{2}$ Organização Mundial do Turismo (OMT). Introdução ao turismo. Trad. Dolores Martins Rodriguez Córner. São Paulo: Roca, 2001.
} 
De acordo com Mota (2001), a partir de meados do século XX, o turismo se tornou um verdadeiro fenômeno de massa acessível às classes médias dos países desenvolvidos e, algum tempo depois, também às classes mais favorecidas dos países em desenvolvimento. A mesma autora comenta que essa atividade turística se originou pela necessidade de deslocamento das populações dentro do espaço físico mundial por diversos motivos. O turismo se tornou bastante acessível a várias camadas da população através de pacotes, financiamentos e empresas que operam com baixo custo (MOTA, 2001).

O turismo é um fenômeno que deve ser observado em diferentes aspectos: no seu contexto histórico, social, ambiental, espacial, político dado sua complexidade e abrangência multidisciplinar (SAMPAIO, 2005).

\subsection{O TURISMO: ATIVIDADE MULTI E INTERDISCIPLINAR}

A produção em conhecimento sobre o turismo, inclusive no Brasil, aumentou significativamente, nos últimos 20 anos, contemplando variadas temáticas relacionadas à área, verificando-se que diversos aspectos do mundo contemporâneo podem ser identificados como fatores geradores do fluxo turístico. Neste aspecto, Dencker (1998), observa o fato de o turismo ser estudado e compreendido a partir de outras disciplinas, como é o caso de grande parte dos cursos de educação em turismo, desenvolvendo a abordagem multidisciplinar ou interdisciplinar, e considera que "[...] isso dificulta a formação de teorias explicativas específicas que sejam suficientes para dar conta do fenômeno turístico" (DENCKER, 1998, p. 36).

Desta forma, a investigação científica do fenômeno turístico tem se respaldado nas ciências sociais, sendo considerado um campo fértil para o conhecimento sobre os aspectos multidisciplinares que o envolvem.

De acordo com a Organização Mundial do Turismo (OMT, 1995), a multidisciplinaridade da investigação turística, implica no conhecimento aplicado em algumas áreas específicas, como a sociologia, a ecologia, o lazer e a educação. Os aspectos sociológicos enfocam as condições sociais que permitem o crescimento da atividade turística, considerando o turismo como fenômeno social e seus reflexos, nos diversos âmbitos que o envolvem (OMT, 1995). Trata-se, portanto, de um fenômeno 
multidisciplinar e interdisciplinar. Multidisciplinar porque tem a participação das seguintes áreas de conhecimento: Administração, Geografia, Lazer, História, Comunicação, Artes, Nutrição, Economia, Contabilidade, Direito e outras como Psicologia, Ecologia, Informática e Estatística. E Interdisciplinar porque todas essas áreas estão interligadas com a atividade do Turismo (OMT, 1995).

Para Menezes e Santos $^{3}$ (apud FARIAS; SONAGLIO, 2013) a multidisciplinaridade está relacionada a matriz curricular das instituições de ensino, esta encontra-se dividida em várias matérias e que ao serem estudadas são "isoladas", não são interligadas a outras disciplinas. Cada matéria contribui com informações próprias do seu campo de conhecimento, sem considerar que existe uma integração entre elas. Essa forma de relacionamento entre as disciplinas é considerada pouco eficaz para a transferência de conhecimentos, já que impede uma relação entre os vários conhecimentos (FARIAS; SONAGLIO, 2013).

A própria OMT (1995) entende que a multidisciplinaridade estabelece limites para o desenvolvimento do saber no turismo. Esse método de estruturação do conhecimento a partir de outras disciplinas, pode reduzir o saber turístico em um elemento altamente dividido e excludente. Neste sentido, Klein ${ }^{4}$ (apud FARIAS; SONAGLIO, 2013, p. 72-73):

[...] acrescenta que em cursos multidisciplinares, perspectivas individuais são apresentadas em série, de forma enciclopédica, deixando as diferenças não examinadas em pressuposições subjacentes e a integração por conta dos alunos. Isto possibilita depreender que a multidisciplinaridade, quando não compreendida em sua totalidade, poderia ocasionar significados confusos diante das interações das disciplinas dispostas nos cursos de turismo, por exemplo.

Como afirma Dencker (1998, p. 42):

Em uma realidade que só pode ser entendida de forma interdisciplinar e que não pode ser submetida a modelos universais de interpretação, torna-se muito importante a criatividade para gerar respostas que atendam a problemas específicos. Isso torna especialmente pertinente o foco em uma educação para o turismo que contemple de forma efetiva a abordagem interdisciplinar como elemento estratégico fundamental para a superação da fragmentação no setor de turismo.

\footnotetext{
3 MENEZES, E. T; SANTOS, T. H. "Multidisciplinaridade" (verbete). Dicionário Interativo da Educação Brasileira - EducaBrasil. São Paulo: Midiamix Editora, 2002.

${ }^{4}$ KLEIN, J. T. Ensino interdisciplinar: didática e teoria. In: FAZENDA, I. C. A. (org.). Didática e interdisciplinaridade. Campinas: SP: Papirus, 1998.
} 
Olhando por este prisma percebe-se então a necessidade de estabelecer um diálogo entre as disciplinas por meio de propostas interdisciplinares, tarefa fundamental das instituições de ensino que tenham a preocupação com o processo integral do conhecimento, não de forma mecânica e fragmentada, mas sim contextualizada e de acordo com as Diretrizes Curriculares Nacionais para o Curso de Graduação em Turismo (BRASIL, 2003). Deve refletir uma dinâmica que atenda aos diferentes perfis de desempenho a cada momento exigidos pela sociedade, através de um profissional adaptável e com a suficiente autonomia intelectual e de conhecimento para que se ajuste sempre às necessidades emergentes, notadamente na expansão do turismo em suas múltiplas modalidades, no Brasil e no mundo (BRASIL, 2003).

Neste contexto, no projeto empreendido se buscou investigar se existia um consentimento comum sobre uma abordagem específica para o ensino de turismo que poderia levar a uma compreensão do processo visando maior reflexão crítica. O cinema, como principal exemplo e objeto deste projeto, encontra lugar de destaque na vida das pessoas. Assistir a um filme no cinema ou TV é prática incorporada de tal modo ao cotidiano de muitas pessoas que parecem estar ali desde sempre. Dessa forma, é preciso se atentar que na contemporaneidade, a mídia exerce uma importante ação pedagógica, sendo que vários estudos apontam para a utilização do cinema como instrumento facilitador da aprendizagem.

Segundo Fabris (2008) os filmes podem ser considerados importantes sistemas de significação, não divertem apenas, também expõem a cultura e a história de povos e lugares. Posicionam os espectadores na fronteira entre ficção e realidade, possibilitam vivenciar uma experiência crítica. Holleben (s./d., s./p.) coloca que "o cinema é espaço de ensino e aprendizagem, pois produz conhecimentos e pode pela pedagogia que veicula ser um aparato sócio cultural comprometido com a transformação da sociedade".

\subsection{CINEMA PARA O ENSINO DO TURISMO}

O uso de filmes oferece aos educadores uma valiosa ferramenta para apresentar informações e conteúdos pedagógicos, pois os alunos podem se beneficiar das imagens que estão sendo apresentadas. Portanto, “os meios de comunicação de massa, tanto 
eletrônicos como impressos, exercem papel fundamental dentro do quadro das sociedades contemporâneas e crescem cada vez mais em importância" (MCQUAIL, 1994, p. 25).

Carvalho (2003) afirma que na era da tecnologia da informação os meios de comunicação de massa exercem papel fundamental na vida das pessoas, se tornando um veículo de registro e difusão de conhecimento. "A linguagem áudio-imagética também tem exercido expressiva influência cultural no mundo contemporâneo, devido os efeitos que ela engendra ao criar uma nova sensibilidade, novos valores, ideias $\mathrm{e}$ comportamentos" (CARVALHO, 2003, p. 1).

Desta forma, considerou-se ser interessante abordar a discussão de Kellner (2001) sobre a cultura da mídia. O autor aponta que a cultura veiculada pela mídia passou a dominar a vida cotidiana, induzindo os indivíduos a identificar-se com as ideologias, as posições e as representações sociais e políticas dominantes e conformarse perante a atualidade social. Complementa afirmando que isso se deve ao prazer propiciado pela mídia, um entretenimento agradável que utiliza instrumentos visuais e auditivos para seduzir o público. "Os estudos culturais delineiam o modo como as produções culturais articulam ideologias, valores e representações de sexo, raça e classe na sociedade, e o modo como esses fenômenos se inter-relacionam" (KELLNER, 2001, p. 39).

Diante disto, no entender de Kellner (2001, p. 20), realiza-se:

[...] uma pedagogia crítica da mídia cujas finalidades são: possibilitar que os leitores e os cidadãos entendam a cultura e a sociedade em que vivem, darlhes o instrumental de crítica que os ajude a evitar a manipulação da mídia e a produzir sua própria identidade e resistência e inspirar a mídia a produzir outras formas diferentes de transformação cultural social.

Segundo Kellner (2001), os estudos culturais desempenham um importante papel na elucidação de conflitos, problemas, desafios e possibilidades que ocorrem na cultura e na sociedade, auxiliando na interpretação da realidade social.

Como a escola trabalha com o saber sistematizado, pode, portanto, instrumentalizar o aluno para que possa compreender e interpretar melhor o mundo e particularmente o cinema, sendo fundamental o educador ver na mídia um aliado para uma mediação mais significativa no processo de ensino-aprendizagem. 
O professor não deve ignorar as informações trazidas de fora por intermédio dos meios de comunicação, mas sim usufruir de tais informações e incorporá-las de forma ativa e construtiva, no intuito de dinamizar o processo de ensino aprendizagem.

Dessa forma, é preciso se atentar que na contemporaneidade, a mídia exerce uma importante ação pedagógica, sendo que vários estudos apontam para a utilização do cinema como instrumento facilitador da aprendizagem. Segundo Fabris (2008) os filmes podem ser considerados importantes sistemas de significação, não divertem apenas, expõem a cultura, a história de povos e lugares. Holleben (s./d., s. p.) coloca que "o cinema é espaço de ensino e aprendizagem, pois produz conhecimentos e pode pela pedagogia que veicula ser um aparato sócio cultural comprometido com a transformação da sociedade".

Fantin (2007) contribui expondo que os filmes, quando bem entendidos no contexto da mídia-educação, podem representar diversas dimensões, entre elas: estéticas, cognitivas, sociais e psicológicas. $\mathrm{O}$ autor reitera ainda que considerar o cinema como um instrumento para educação significa que contar histórias com imagens, sons e movimentos, pode atuar na consciência do sujeito, e no âmbito sócio-políticocultural, tornando-se importante elemento de intervenção, pesquisa, comunicação e principalmente, educação.

\section{METODOLOGIA}

Como citado anteriormente, a presente pesquisa está vinculada ao Projeto de Extensão Cinema e Educação, desenvolvido na Universidade Estadual do Paraná UNESPAR - Campus Apucarana (FECEA), com parceria do Centro de Estudos Aplicados ao Turismo da UNESPAR campus Apucarana (CEETUR). No projeto em questão se realizou encontros quinzenais com 4 rodadas temáticas unindo conteúdos a serem trabalhados e discutidos. Uma das temáticas abordadas voltou-se especificamente ao curso de turismo com a exposição de filmes voltados às disciplinas do curso. Os filmes foram exibidos para as quatro turmas do curso durante os meses de maio e junho do ano de 2016, sendo eles: Diários de Motocicleta (Walter Salles, 2004); Falando Grego (Donald Petrie, 2009); Iracema - uma transa Amazônica (Jorge Bordanzky; 
Orlando Senna, 1975) e Comer, Rezar e Amar (Ryan Murphy, 2010). É importante ressaltar que estes filmes foram selecionados considerando suas temáticas e a possibilidade de unir os conteúdos a serem trabalhados e discutidos com as áreas envolvidas no curso.

Após cada exibição foram feitas discussões com um mediador previamente escolhido de acordo com as possibilidades de temas a serem abordados e os participantes. Em seguida todos os participantes responderam a um questionário avaliativo com perguntas abertas e fechadas sobre a prática desenvolvida.

Os questionários foram tabulados e analisados, e os resultados obtidos subsidiaram a análise a ser apresentada no presente artigo.

\subsection{CONTEXTUALIZAÇÃO DOS FILMES APRESENTADOS}

As resenhas abaixo foram retiradas de sites especializados sobre críticas de filmes cinematográficos para contextualizar o leitor sobre cada um dos filmes apresentados, e sobre os temas trabalhados pelos mediadores em cada filme.

\subsubsection{Comer, Rezar, e Amar}

É um livro da escritora Elizabeth Gilbert, de 2010, que conta sua história. Dirigido por Ryan Murphy, o filme também de 2010, apresenta a história de Elizabeth, personagem vivida por Julia Roberts, a qual descobre que sempre teve problemas nos seus relacionamentos amorosos. Ela tinha tudo o que uma mulher moderna sonha: "um marido, uma casa, uma carreira bem-sucedida" ainda sim, como muitas outras pessoas, ela está perdida, confusa e em busca do que realmente deseja na vida. Divorciada e num momento decisivo, Gilbert sai da zona de conforto, arriscando tudo para mudar sua vida, embarcando em uma jornada ao redor do mundo que se transforma em uma busca por autoconhecimento. Em suas viagens, ela descobre o verdadeiro prazer da gastronomia na Itália, o poder da oração na Índia, e, finalmente e inesperadamente, a paz interior e equilíbrio de um verdadeiro amor em Bali (ADORO CINEMA, s/d.a). 
O mediador realizou uma abordagem geográfica sobre a Itália, Índia e Indonésia - ocupação territorial dos espaços; dados sobre as populações, arquitetura, turismo, gastronomia, religião, usos e costumes.

\subsubsection{Iracema - uma transa Amazônica}

De acordo com o site Filmes Cult (s./d.), em 1974, em plena ditadura, quando o governo militar alardeava a propaganda da construção do "Brasil Grande", Jorge Bodanzky, Orlando Senna e Wolf Gauer filmam Iracema - uma transa amazônica, ficção com uma feição documental que se tornou marco na cinematografia brasileira. $\mathrm{O}$ filme faz um contraponto à propaganda oficial da época sobre a Amazônia, revelando as queimadas, o trabalho escravo e a prostituição infantil através da história da menina ribeirinha Iracema, que, atraída pela cidade grande e pela lábia do motorista de caminhão Tião Brasil Grande, acaba se prostituindo às margens da rodovia Transamazônica. Proibido durante seis anos no Brasil, recebeu inúmeros prêmios em festivais internacionais (FILMES CULT, s./d.). Em 1981, foi o grande vencedor do Festival de Brasília do Cinema Brasileiro (FILMES CULT, s./d.).

O mediador fez uma analogia entre a obra literária de José de Alencar - Iracema a virgem dos lábios de mel e o filme teuto-brasileiro. Amazonas - o contexto histórico e atual da Trans Amazônica.

\subsubsection{Falando grego}

Na obra dirigida por Donald Petrie no ano de 2009, o site Adoro Cinema (s./d.c) mostra que Georgia personagem vivido por Nia Vardalos, é uma americana de origem grega que trabalha como guia de turimo na Grécia. De acordo com a mesma fonte sua vida é extremamente entediante e ela vive sempre cansada, pois os turistas parecem curtir mais as compras do que aprender alguma coisa sobre o país. Hotéis baratos, ônibus velho, calor infernal e turistas "engraçadinhos" tornaram Georgia uma mulher frustrada. Até o dia em que Irv Gordon (Richard Dreyfuss), um turista muito especial, aparece. Com seu senso de humor ele tenta mostrar todas as possibilidades de viver bem, ser feliz e não perder a chance de ter um grande amor. (ADORO CINEMA, s./d.c) 
O mediador abordou os conteúdos relacionados à Grécia - perspectivas históricas, culturais e econômicas. Discussões sobre a crise econômica grega e brasileira. Dados sobre a atividade turística na Grécia.

\subsubsection{Diários de Motocicleta}

De acordo com o site Adoro Cinema (s./d.b), Diários de Motocicleta produzido por Walter Salles, de 2004, é baseado no livro de memórias de mesmo nome escrito por Ernesto Guevara de 23 anos, que mais tarde se tornaria o comandante Che Guevara. A mesma fonte cita que o filme conta a história de Ernesto de La Serna (Che Guevara) um jovem estudante de Medicina que, em 1952, decide viajar pela América do Sul com seu amigo Alberto Granado. A viagem é feita de moto, que acaba quebrando após 8 meses. Eles então passam a seguir viagem através de caronas e caminhadas, sempre conhecendo novos lugares. Porém, quando chegam a Machu Pichu, a dupla conhece uma colônia de leprosos e passam a questionar a validade do progresso econômico da região, que privilegia apenas uma pequena parcela da população (ADORO CINEMA, s./d.b)

O mediador discutiu com os participantes os temas: América do Sul na atualidade - uma abordagem cultural, gastronômica e turística através da experiência de uma viagem pelas principais localidades por onde Ernesto Guevara de La Serna (Che) passou durante sua expedição em 1952.

\section{ANÁLISE DOS RESULTADOS}

A participação dos alunos e professores foi fundamental para a realização do projeto e também para a análise dos resultados. Percebeu-se que tanto alunos quanto professores gostaram da exibição dos filmes propostos, classificando-os como satisfatórios e adequados ao que se propunha, concordando que a maneira como os assuntos relacionados a ele foram expostos permitindo trazer contribuições para seu processo de aprendizagem. 
Também foi possível perceber que quanto ao uso do cinema pelo professor, houve o envolvimento destes para com o cinema. No entanto, no universo de 22 professores que ministravam aulas para o curso de Turismo no ano letivo de 2016, somente 10 dos professores questionados usavam este recurso em sala de aula pelo menos 1 vez no bimestre e consideravam importante usar o cinema como recurso pedagógico, sendo 6 destes professores de disciplinas específicas. Consideraram ainda que a exibição de um filme motivava o aluno despertando-lhe a curiosidade pelo conteúdo a ser explorado. Não ficou claro se o filme usado era apenas para introduzir um conteúdo ou se através dele eram discutidos e relacionados os assuntos, facilitando o entendimento do aluno.

Quanto aos alunos, em um universo de 82 alunos considerando as quatro turmas do curso, houve uma média de participação de 70 alunos nas quatro exibições. Destes participantes 67 afirmaram que o filme facilitava a aprendizagem, deixava a aula mais atrativa e eles conseguiam assim, estabelecer relações do conteúdo do filme ao seu cotidiano. Mas em relação aos conteúdos não ficou claro se eles realmente interpretavam o filme ou apenas o achavam interessante. Porém, mostraram também que nem em todos os filmes escolhidos pelo professor era fácil de estabelecer as relações com os cotidianos da sala de aula e suas vidas e que se tornavam maçantes.

Embora os resultados tenham sido favoráveis ao uso do cinema como recurso didático pedagógico, percebeu-se um problema, não apontado pelos professores, mas que pôde ser facilmente verificado é que os filmes acabavam sendo utilizados como um recurso ilustrativo e não como desencadeadores de discussões ou promotores de uma educação do sensível. O cinema na sala de aula ainda estava sendo visto como um entretenimento e não como uma possibilidade de conteúdo.

\section{CONSIDERAÇÕES FINAIS}

As experiências associando a educação e cinema evidenciadas na análise dos resultados trouxeram resultados alentadores, abrindo espaço para novas perspectivas na formação escolar podendo ser consideradas essenciais na formação acadêmica, independentemente do nível desta formação. Algo nitidamente perceptível na presente pesquisa é que os professores precisariam de uma orientação sobre como melhor utilizar 
este recurso em sala de aula para conseguir alcançar todos os benefícios da prática, visto que os filmes, quando utilizados, na maioria das vezes acabam se tornando apenas um recurso ilustrativo e não um recurso didático pedagógico capaz de gerar discussões, contribuir com o ensino do conteúdo e promover uma educação sensível com olhar mais amplo.

Práticas pedagógicas como esta favorecem o aprendizado dos alunos e proporcionam compreensão do todo, relacionando outros conteúdos estudados e, portanto abrindo perspectivas para a consolidação da interdisciplinaridade como facilitadora do ensino do turismo nas universidades. Porém não basta só estar previsto como proposta do curso, pois os projetos interdisciplinares exigem um grande comprometimento na busca dos temas a serem trabalhados e na maneira como são desenvolvidos em um curso de turismo. Trabalhar com a interdisciplinaridade exige intencionalidade e comprometimento. Por isso o uso de filmes poderia facilitar esta integração entre os professores do curso.

\section{REFERÊNCIAS}

ADORO CINEMA (a). Comer Rezar e Amar. Disponível em: <http://www.adorocinema.com/filmes/filme-121807/>. Acesso em: 29/06/2017.

ADORO CINEMA (b). Diários de Motocicleta. Disponível em: <http://www.adorocinema.com/filmes/filme-33464/>. Acesso em: 29/06/2017.

ADORO CINEMA (c). Falando Grego. Disponível em: <http://www.adorocinema.com/filmes/filme-143114/>. Acesso em: 29/06/2017.

BARRETTO, M. Manual de iniciação ao estudo do turismo. Campinas, São Paulo: Editora Papirus, 2003.

BERNADET, J. C. O que é cinema. 9. ed. São Paulo: Brasiliense, 2006.

BLASCO, P. G.; GALliAN, D. M. C.; RONCOLETTA, A. F. T.; GRAZIELA MORETO, G. Cinema para o Estudante de Medicina: um Recurso afetivo e efetivo na educação humanística. In: Revista Brasileira de Educação Médica, v. 29, n. 2, 2006. Disponível em: <http://docplayer.com.br/10306331-Cinema-para-o-estudante-demedicina-um-recurso-afetivo-efetivo-na-educacao-humanistica.html>. Acesso em: 25/06/2017.

BODANZKY, J.; SENNA, O. Iracema Uma Transa Amazônica. Produção: Jorge Boanzky; Hermano Penna. Brasil. Embrafilme, 1974, 1 DVD. 
BRASIL. Diretrizes Curriculares Nacionais do Curso de Graduação em Turismo, 2003. Disponível em: <http://portal.mec.gov.br/cne/arquivos/pdf/CES_0288.pdf>. Acesso em: 12/07/2017.

BRASIL, Ministério do Turismo. Turismo cultural: orientações básicas. 3. ed. Brasília: Ministério do Turismo. 2010. Disponível em: <http://www.turismo.gov.br/sites/default/turismo/o_ministerio/publicacoes/downloads_ publicacoes/Turismo_Cultural_Versxo_Final_IMPRESSxO_.pdf $>$. Acesso em: $12 / 06 / 2017$.

BRASIL, Ministério do Turismo. Estudo de sinergia e desenvolvimento entre as indústrias do Turismo e audiovisual brasileira. 2007. Disponível em: $<$ http://www.turismo.gov.br/sites/default/turismo/o_ministerio/publicacoes/downloads_ publicacoes/Estudo_Completo_Cinema.pdf>. Acesso em: 15/06/2017

CARVALHO, E. J. Gonçalves de. Conhecimento da História e da Educação: o cinema como fonte alternativa. In: Revista Comunicações - Revista do Programa em PósGraduação em Educação da Universidade Metodista de Piracicaba, ano 10, n. 2, Dez./2003, p. 183-193. Disponível em:

<http://www.dtp.uem.br/lap/publicacoes/conhecimento-da-historia-e-da-educacao-ocinema-como-fonte-alternativa>. Acesso em: 13/06/2017.

COSTElA, A. F. Comunicação: Do grito ao satélite - História dos Meios de Comunicação. 5. ed. Campos do Jordão: Mantiqueira, 2002.

DENCKER, A. F. M. Métodos e técnicas de pesquisa em turismo. São Paulo: Futura 1998.

DIAS, R.; AGUIAR, M. R. Fundamentos do Turismo. São Paulo: Alínea, 2002.

FABRIS, E. H. Cinema e Educação: um caminho metodológico. In: Educação X Realidade. V. 33, n. 1, jan./jun., 2008, p.117-134. Disponível em: <http://seer.ufrgs.br/index.php/educacaoerealidade/article/view/6690/4003>. Acesso em: $22 / 06 / 2017$.

FANTIN, M. Mídia - Educação e Cinema na Escola. In: TEIAS: Rio de Janeiro, ano 8, n. 15-16, jan./dez., 2007. Disponível em: <www.nica.ufsc.br/../doc_download/11midia-educacao-e-cinema-na-escola.PDF>. Acesso em: 02/07/2017.

FARIAS, M. F. de; SONAGLIO, K. E. Perspectivas multi, pluri, inter e transdisciplinar no turismo. In: Revista Iberoamericana de Turismo- RITUR, Penedo, v. 3, n. 1, p. 71-85, 2013. Disponível em: <http://www.seer.ufal.br/index.php/ritur>. Acesso em: 02/06/2017.

FILMESCULT. Iracema, Uma transa amazônica. Disponível em: $<$ http://filmescult.com.br/iracema-uma-transa-amazonica-1975/>. Acesso em: 10/06/2017. 
FURUNO, F. A evolução das mídias e a internet: cultura participativa transformando os meios de comunicação. Dissertação (Mestrado em Comunicação). Universidade Anhembi Morumbi. São Paulo, p. 27. 2010.

HOLlEBEN, I. M. A. D. S. CiNEMA E EDUCAÇÃo: DiÁlogo POSSÍVEL. UEPG. Disponível em:

<http://www.diaadiaeducacao.pr.gov.br/portals/pde/arquivos/462-2.pdf>. Acesso em: 03/07/2017.

KELLNER, D. A cultura da mídia: estudos culturais - identidade e política entre o moderno e o pós-moderno. São Paulo: EDUSC, 2001.

KLAMMER, C. R.; GNOATTO, D. M.; OZÓRIO, É. V. K.; SOLIERIR, M. Cinema e Educação: possibilidades, limites e contradições. Trabalho apresentado no III Simpósio Nacional de História Cultural, Florianópolis, UFSC, 2006, p. 872 - 882. Disponível em: $<: / /$ minhateca.com.br/tuca.americo/Biblioteca(1)/Cinema/J+K+L/KLAMMER*2c+C.R. +et+al.++Cinema+e+Educa*c3*a $7 * \mathrm{c} 3 * \mathrm{a} 3 \mathrm{o}+* 7 \mathrm{e}+$ Possibilidades*2c+Limites+e+Contra di*c3*a7*c3*b5es,890490733.pdf>. Acesso em: 23/05/2017.

MARCELlO, F. A.; FISCHER, R. M. B. Tópicos para Pensar a Pesquisa em Cinema e Educação. In: Educação X Realidade. V. 36, n. 2, mai./ago., 2011, p. 505-519. Disponível em:

<seer.ufrgs.br/educacaoerealidade/article/download/16944/12912.PDF>. Acesso em: $12 / 06 / 2017$.

MCQUAIL, D. Lecture on 'Media Accountability', University of Amsterdam, 17 March, 1994. Disponível em:

<http://journals.sagepub.com/doi/abs/10.1177/0267323195010004007>. Acesso em: 13/07/2017.

MOTA, K. C. N. Marketing Turístico: promovendo uma atividade Sazonal. São Paulo: Atlas, 2001.

MURPHY, Ryan. Comer, Rezar e Amar. Produção: Brad Pitt; Dede Gardner. EUA: Sony Pictures, 2010, 1 DVD.

NAKASHIMA, S. K.; CALVENTE, M. del C. M. H. História do Turismo: epítome das mudanças. In: Revista Turismo e Sociedade. Curitiba, v. 9, n. 2, maio-agosto, 2016, p.1-20. Disponível em: <http://revistas.ufpr.br/turismo/article/view/43151>. Acesso em: $31 / 12 / 2018$.

NAPOLITANO, M. Como usar o cinema na sala de aula. São Paulo: Contexto, 2003.

PERLIN, A. K. Turismo cinematográfico: potencialidades das produções cinematográficas como fator de atração turística. Trabalho de Conclusão de Curso. Centro Universitário La Salle - UNISALLE. CANOAS, 2010. 72f. 
PETRIE, D. Falando Grego. Produção: Tom Hanks; Rita Wilson. EUA, Imagem Filmes, 2009, 1 DVD.

PRETTO, N. de L. Uma escola sem/com Futuro: educação e multimídia. Campinas/SP: Papirus, 1996.

SALLES, W. Diários de Motocicleta. Produção: Edgard Tenenbaum; Karen Temkhoff; Michael Nozik. Argentina: Buena Vista Home Enterteinment, 2004, 1 DVD.

SAMPAIO, C. A. C. Turismo como fenômeno humano: princípios para pensar a socioeconomia e sua prática sob a denominação turismo comunitário. Santa Cruz do Sul: EDUNISC, 2005.

TURNER, G. Cinema como prática social. São Paulo: Summus, 1988.

VESCE, G. E. P. Relação entre Cinema e Educação. Disponível em: $<$ http://www.infoescola.com/pedagogia/relacao-entre-cinema-e-educacao>. Acesso em: 12/07/2017.

WEBCINE. História do Cinema. 1998. Disponível em: <http://www.webcine.com.br>. Acesso em: 16/05/2017.

Recebido em: 30-07-2017.

Aprovado em: 30-08-2017. 